\title{
External Anatomy and Life Cycle of Aphis nasturtii (Hemiptera: Aphididae)
}

\author{
Liana Mihaela Fericean ${ }^{1^{*}}$ and Mihaela Corneanu ${ }^{2}$ \\ ${ }^{1}$ Department Biology and Plant Protection, Faculty of Agriculture, Banat's University \\ of Agricultural Sciences and Veterinary Medicine "King Michael I of Romania" from \\ Timişoara Aradului Street, nr.119, 300645, Timisoara \\ ${ }^{2}$ Department Genetic Engineering, Faculty of Horticulture, Banat's University of \\ Agricultural Sciences and Veterinary Medicine "King Michael I of Romania” from \\ Timişoara Aradului Street, nr.119, 300645, Timisoara
}
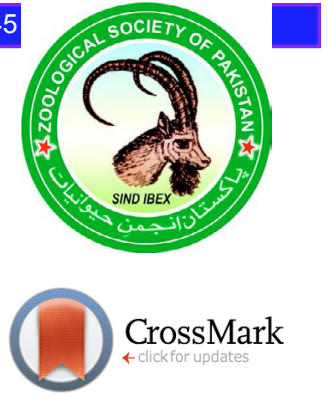

Article Information
Received 27 June 2017
Revised 30 July 2017
Accepted 07 November 2017
Available online 15 November 2017
Authors' Contribution
Both authors conceived and designed
the study. Mf collected and analyzed
data and wrote the article. MC
performed biometrical measurements
and statistical analysis.
Key words
Biometrical Measurements, Biology,
Aphis nasturtii, External morphology,
Ecology.

\begin{abstract}
A B S T R A C T
Aphis nasturtii (Kaltenbach) is a cosmopolitan species who can cause direct damage to the plants by extracting the sap, and indirectly it is a vector to 16 plant viruses. The study presents data referring to the external morphological characteristics, to the biometrical measurements and to the life cycle of Aphis nasturtii. The researches have been carried out for a period of four years on the potato and for a period of two years on the orchards from Romania. At the Aphis nasturtii species the smallest length of the body found for aphids captured in Romania was $1.10 \mathrm{~mm}$, while the biggest was $2.40 \mathrm{~mm}$. In the conditions of the Western part of Romania Aphis nasturtii winter egg stage started in October. On the primary host the aphids gave birth parthenogenetically to three generations of fundatrigenous. In July, the winged form migrated to the secondary host, where successive generations have been born through parthenogenetic reproduction. Gynopara in October return to the primary host and give birth to wingless oviparae that mate with males and lay winter eggs. The biometrical measurements of Aphis nasturtii help to complete knowledge on external morphology of this species. By knowledge of biology and ecology of Aphis nasturtii a protocol for the prevention and control can be established.
\end{abstract}

\section{INTRODUCTION}

$\mathrm{B}$ uckthorn aphid, Aphis nasturtii is a member of the order Hemiptera, suborder Aphidinea, superfamily Aphidoidea, family Aphididae. This aphid is nearly globally distributed, located in all but the coldest terrestrial habitats. It has a broad host range, having been recorded on species of over 60 plant families (Blackman and Eastop, 2006), affect various field crops, fruits and vegetables as sucking pests (Aheer et al., 2008; Arshad et al., 2017). Aphis nasturtii is an important vector of potato viruses. It transmits potato viruses $\mathrm{Y}$ and A, and potato leaf roll virus (Foster, 2006), beet yellows, and cucumber mosaic virus (Kennedy et al., 1962). Blackman and Eastop (2006) found that this species is implicated in the transmission of at least 15 plant viruses. The buckthorn aphid infests the lower leaves of potato (Dixon et al., 1993). Worldwide, aphids are one of the major problems from two reasons: aphid feeding can cause direct damages by extracting sap, and indirectly by sending a large number of phytopathogenic viruses. Given these considerations, and that there is not enough research on external anatomy and biology of Aphis nasturtii,

\footnotetext{
Corresponding authors: liana.fericean@gmail.com 0030-9923/2017/0006-2141 \$ 9.00/0

Copyright 2017 Zoological Society of Pakistan
}

the research can make notable contributions in this area. Knowing the life cycle of Aphis nasturtii can be essential to effective control measures.

\section{METHODS}

The research has been carried out for a period of six years. The biology of Aphis nasturtii was observed for four years: 2005 - 2008 on potato culture, and in 2015 2016 in various orchards from Romania.

Alate aphid were collected and preserved in ethanol $80 \%$. Aphids were mounted on slides according to the method of Blackman and Eastop (2000). The biometrical measurements of Aphis nasturtii was done for a total of 300 individuals, species captured from, potatoes and orchards from Didactic Station Timisoara (Timiş County - a plain area) and Varfurile, (Arad County - a mountain area) from Romania. The data were statistically analyzed.

Morphometric approaches have been used widely to differentiate between closely related species, populations and biotypes in various insects (Lozier et al., 2008; Barahoei et al., 2011; Lamb, 2011; Ruiz et al., 2014). In aphids alone, there have been a series of studies involving the application of multivariate techniques to the study of morphological variation (Blackman and Spence, 1994; Kawada, 1997; Remaudiere, 1997; Blackman, 2000; Perju, 
2004; Fericean et al., 2006; Williams and Dixon, 2007; Fericean et al., 2012; Mehrparvar et al., 2012; Ruiz, 2014).

In our study the body length was measured from the middle of the frons on the head to the end of the abdomen. The length of the head and thorax was measured from the frons of the head, but does not include antennal tubercles, to the end point of the third segment of the thorax. The length of the abdomen was measured from the last segment of the thorax to the end point of the eighth abdominal segment, but does not include the cauda or the siphunculus.

The aphids have been collected with yellow vessel traps on three day intervals.

To accurately determine the species the work made by Blackman and Eastop (2000 a,b) have been consulted.

\section{RESULTS AND DISCUSSION}

Apterous adult of Aphis nasturtii have yellow sometime to green color, ovoid body and there is not wax-powdered. The head has no antennal tubercles. The antennae are shorter than the body with a dark apex. Siphunculi are cylindrical and sometimes they can be light brown to the apex. The tail is short and sharp.

The alata have a length of $1.10-2.40 \mathrm{~mm}$, they are pale green to pale yellow on the back and on each side. The head and the three segmented middle region of the body are black, the thorax bearing 2 pairs of wings. The third main body region of the aphid, consisting of eight segments, is pale without dark bands. The cauda (extension of the eighth abdominal segment) is sharp and siphunculi on the dorsal or lateral surface of sixth abdominal segment are black towards the apex, much longer that the cauda.

Figure 1 shows that, out of a total of 300 individuals of the species Aphis nasturtii, the smallest length of the body established for aphids captured in West Zone of Romania was $1.10 \mathrm{~mm}$, while the biggest was $2.40 \mathrm{~mm}$. The average body length was $1.77 \pm 0.20 \mathrm{~mm}$. The results are similar to those in the literature (Dubnik, 1991), which states that the body length of Aphis nasturtii ranges from $1.20-2.10 \mathrm{~mm}$.

By analyzing the data presented in the Table 1 regarding the length of the head and thorax, it may be noticed that the maximum length of these parts was 0.90 $\mathrm{mm}$ and minimum length was $0.50 \mathrm{~mm}$. The average value calculated for the length of these parts was $0.71 \pm 0.11$ $\mathrm{mm}$.

The minimum width of head was $0.20 \mathrm{~mm}$ and the maximum width of head was $0.40 \mathrm{~mm}$. The average value calculated for head width was $0.31 \pm 0.04 \mathrm{~mm}$.

As far as the thorax width is concerned, it was minimum $0.40 \mathrm{~mm}$ and maximum $0.80 \mathrm{~mm}$. Mean thorax width was $0.61 \pm 0.07 \mathrm{~mm}$
Analyzing data on the length and width of the abdomen, it can be seen that the minimum length of the abdomen was $0.60 \mathrm{~mm}$ and minimum width was $0.50 \mathrm{~mm}$, the maximum length of the abdomen was $1.50 \mathrm{~mm}$ and the maximum width was $1 \mathrm{~mm}$. The mean length of the abdomen was $1.04 \pm 0.10 \mathrm{~mm}$, while the average value calculated for abdomen width was $0.78 \pm 0.10 \mathrm{~mm}$.

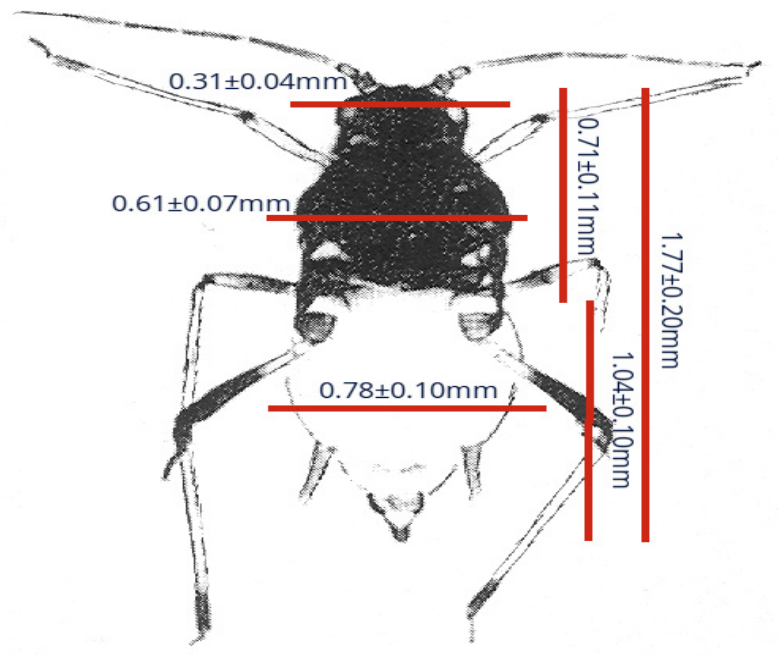

Fig. 1. The body length of Aphis nasturtii

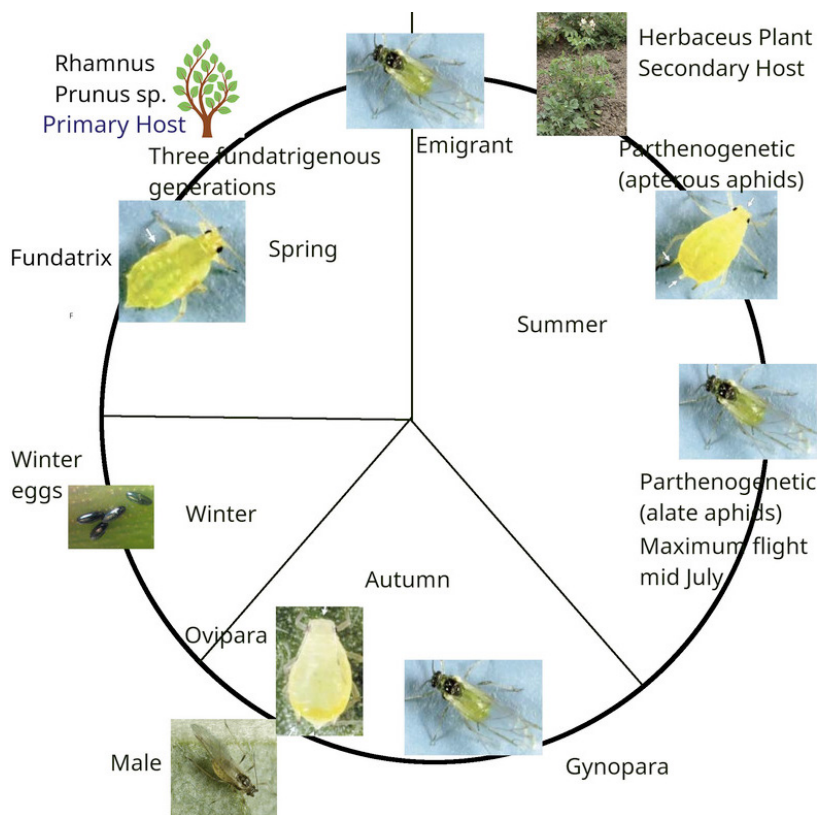

Fig. 2. Life cycle of Aphis nasturtii

Recent studies have reported that is not uncommon to find different species of aphids clustering together when feeding to create a sink effect which improves the flow of nutrients (Brightwell and Dransfield, 2015). 
Table I.- Biometrics measures Aphis nasturtii

\begin{tabular}{|c|c|c|c|c|c|c|}
\hline & \multirow{2}{*}{$\begin{array}{l}\text { Body length } \\
(\mathrm{mm})\end{array}$} & \multirow{2}{*}{$\begin{array}{l}\text { Head+thorax length } \\
(\mathrm{mm})\end{array}$} & \multirow{2}{*}{$\begin{array}{l}\text { Head width } \\
(\mathrm{mm})\end{array}$} & \multirow{2}{*}{$\begin{array}{l}\text { Thorax width } \\
(\mathrm{mm})\end{array}$} & \multicolumn{2}{|c|}{ Abdomen (mm) } \\
\hline & & & & & Length & Width \\
\hline Average & 1.77 & 0.71 & 0.31 & 0.61 & 1.04 & 0.78 \\
\hline Average deviation & 0.20 & 0.11 & 0.04 & 0.07 & 0.10 & 0.10 \\
\hline Standard deviation (s) & 0.27 & 0.14 & 0.06 & 0.09 & 0.14 & 0.14 \\
\hline (m) Min & 1.10 & 0.50 & 0.20 & 0.40 & 0.60 & 0.50 \\
\hline (M) Max & 2.40 & 0.90 & 0.40 & 0.80 & 1.50 & 1 \\
\hline
\end{tabular}

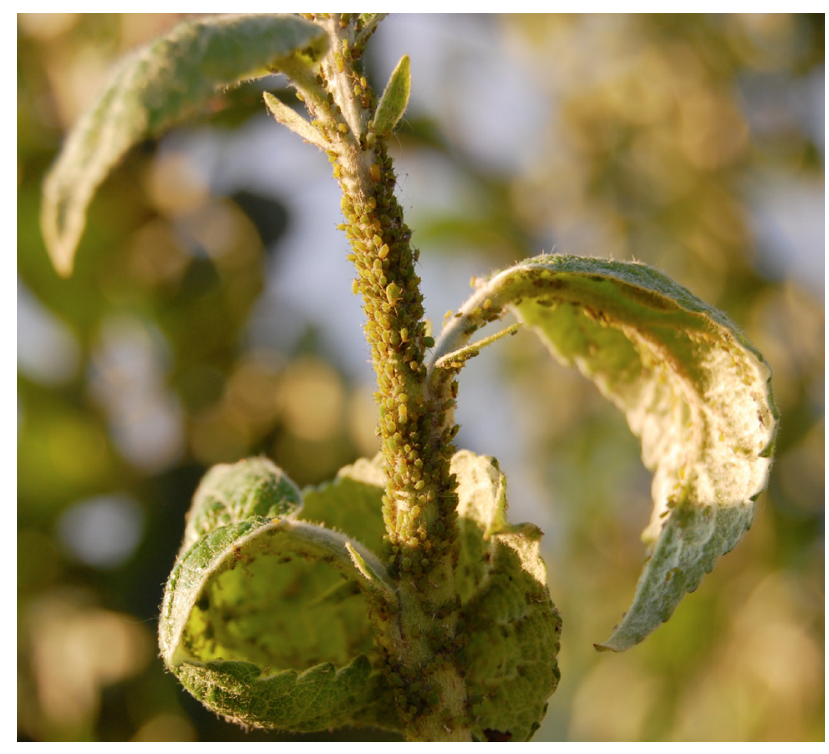

Fig. 3. Colony of Aphis nasturtii and Aphis pomi

We find in orchard some mixed species colonies of Aphis nasturtii living with Aphis pomi (Fig. 3).

According to Williams and Dixon (2007) and Blackman and Eastop (2000) the life cycles of aphids can be divided into two types based on how they utilize their host plant: 1. Non host alternating life cycle (monoecious or autoecious) in which the aphid feed and reproduce on only one host plant during the whole year 2. Host alternating life cycle (heteroecious) in which aphid have two types of host plants.

In our country, Aphis nasturtii is a heteroecious species, the primary host plant is Malus spp. and secondary host plant is potatoes and other herbaceous plants.

The life cycle of aphid is among the most remarkable of all insect groups.

In the condition of the Western part of Romania (Fig. 2), Aphis nasturtii overwinter in the egg stage in October usually on the stems of Malus spp. In the beginning of the spring in first decade of March in plain area and second decade of March in mountain area, the eggs hatch out into wingless female nymphs which are termed fundatrix. These begin to reproduce by parthenogenesis and give birth to other daughter aphids without any fertilization. Kawada (1997) mentioned that aphid lifespan within an asexual lineage is generally short, within a few days (7-10 days), thus they soon became adults.

On the primary host Mallus spp. the aphids gave birth parthenogenetically to three generations of apterous fundatrigenous. The aphid daughters develop wings. These winged daughters fly off to an herbaceous plant. The winged forms have two pairs of wings of which the hind pair is quite small.

Alford (1994) discovered that in June, the winged form migrated to the secondary host, a large variety of plant including potatoes, tomatoes and other herbaceous plant.

In the climatic condition of our country Aphis nasturtii migrated to the secondary host - potatoes in the first decade of July, in the $2005-2008$ period, the maximum flight took place from July 10 to 25 .

In orchards, in the $2015-2016$ period, the maximum flight was recorded in the second part of May and first part of June while in August no specimen have been captured.

On the secondary host take place a parthenogenetic reproduction. Gynopara in October return to the primary host and give birth to wingless sexual female, oviparae that mate with males and lay winter eggs.

Egg laying occurs in October until mid - November on buds leaves and bark of trees. The egg is attached to the support through a sticky substance which is eliminated together with the egg and hardens quickly. Number of eggs deposited by ovipara is 3 to 5 and are generally resistant at frozen conditions Dubnik (1991).

Aphis nasturtii may produce great damage on plant, they suck the sap out of plants and may inject a toxin into plants which causes leaves to curl and further distorts growth (Fig. 4).

Ant and aphid develop symbiotic relationships which help defend them in their environment. Ozdemir et al. (2008) recorded Lasius alienus attending buckthorn - 
potato aphid in Turkey, and Shiran et al. (2013) similarly recorded Tapinoma simrothi and Lepisiotra bipartite in Iran.

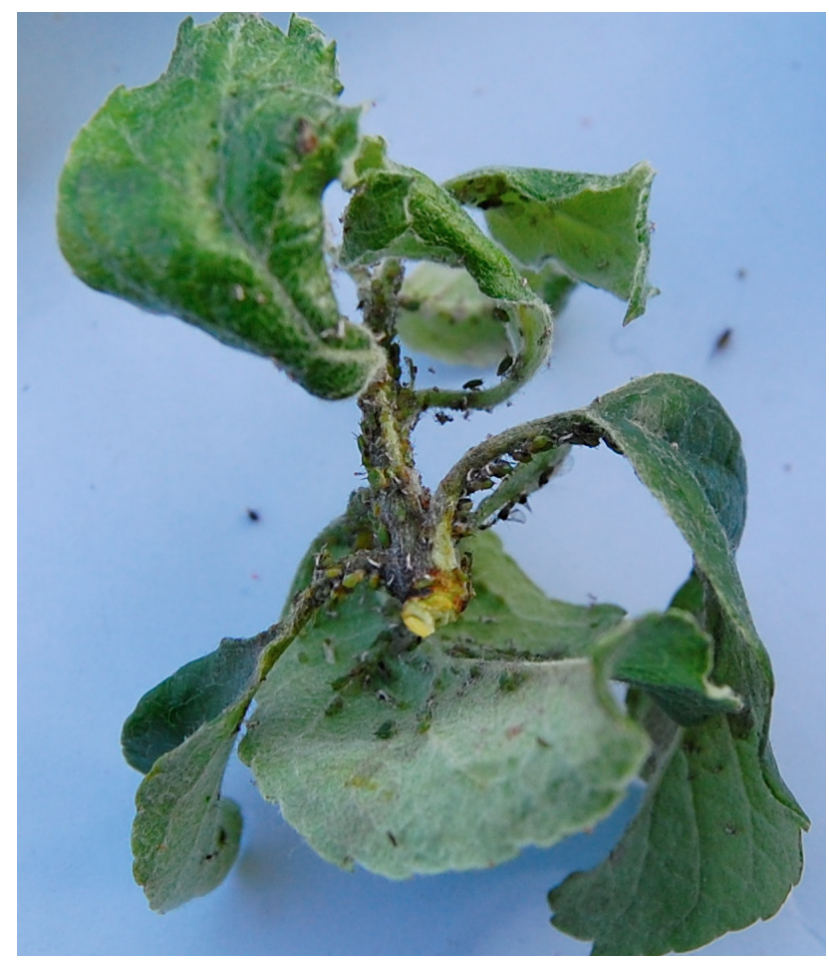

Fig. 4. Damage of aphid attack

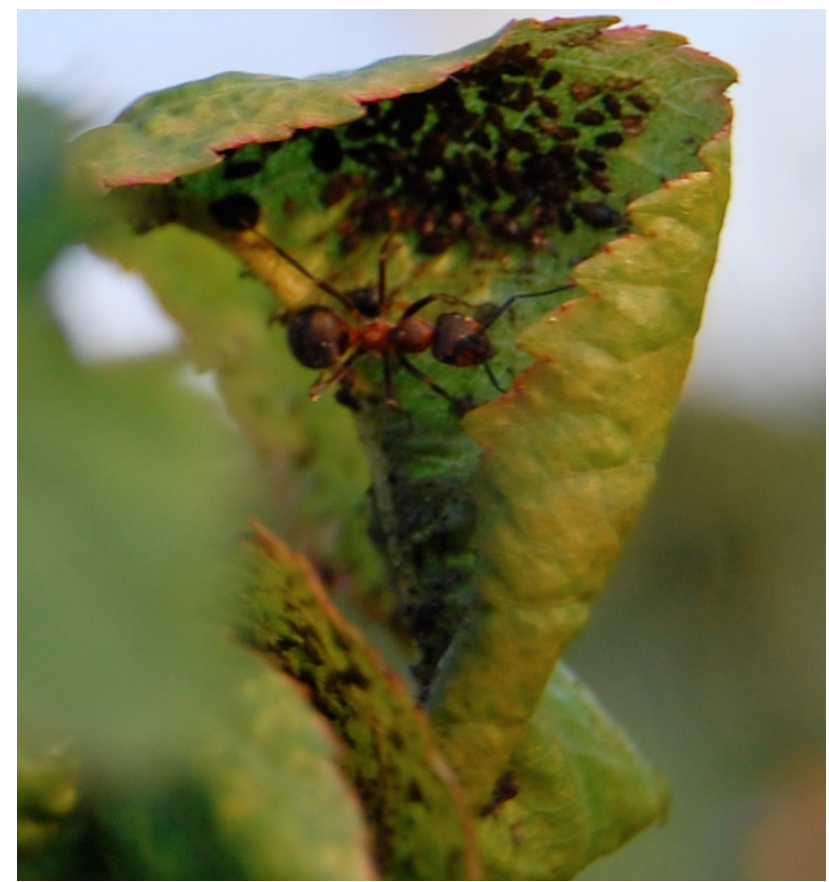

Fig. 5. Aphids - ants relation
In the condition of the Western part of Romania relationships between ants and aphids were also observed (Fig. 5). These relationships are mainly mutualistic where both the ants and aphids benefit. Aphids secret the honeydew who is a sugar-rich sticky liquid that the ants are feeding with and the ants protect the aphid and incorporate the aphid territory into their own territory.

\section{CONCLUSIONS}

The results concluded that the smallest length of the body of Aphis nasturtii established for aphids captured in Romania was $1.10 \mathrm{~mm}$, while the biggest was $2.40 \mathrm{~mm}$, with an average $1.95 \pm 0.24 \mathrm{~mm}$. On the primary host, the maximum flight was recorded in the second part of May and first part of June and not being captured in August. On the second host (potatoes), the flight infection takes place in July.

Knowing the biology and ecology of Aphis nasturtii we can can establish a protocol for the prevention and control of the aphids, protocol that leads to optimal timing of treatement application. Due to the fact that in the orchards, the maximum flight was recorded in the second part of May and the first part of June, the recomended measures are to combat this pest in May and June while in July and August there are no required interventions. In the potatoes cultures, on the other hand, it is recomended to take measures in second and third decade of July. The application of pesticides have an adverse effects on the environment and on humans and it is recomended optimal timing of treatement application in the period when plants are most vulnerable to damage by aphids avoiding unnecessary use of pesticide substances.

\section{ACKNOWLEDGMENTS}

This work was supported by the grant number 2753/30.04.2015, awarded in the internal grant competition of the Banat's University of Agricultural Sciences and Veterinary Medicine "King Michael I of Romania".

\section{Statement of conflict of interest}

Authors have declared no conflict of interest.

\section{REFERENCES}

Alford, D.V., 1994. Ravageurs des vegetaux d'ornament, arbres, arbustes, fleurs, INRA, Paris.

Aheer, G.M., Ali, A. and Munir, M., 2008. Abiotic factors effect on population fluctuation of alate aphids in wheat. J. agric. Res., 46: 367-371.

Arshad, M., Khan, H.A.A, Hafeez, F., Sherazi, R. and 
Iqbal, N., 2017. Predatory potential of Coccinella septempunctata L. against four aphid species Pakistan J. Zool., 49: 623-627.

Barahoei, H., Madjdzadeh, S.M. and Mehrparvar, M., 2011. Morphometric differentiation of five biotypes of Lysiphlebus fabarum (Marshall) (Hymenoptera: Braconidae: Aphidiinae) in Iran. Zootaxa, 2745: $43-52$

Blackman, R.L. and Eastop V., 2000 a. Aphids on the world's crops: An identification and information guide, John Wiley \& Sons Ltd.

Blackman, R.L. and Eastop, V., 2006. Aphids on the world's herbaceous plants and shrubs. Vols 1 \& . J. Wiley \& Sons, Chichester, UK

Blackman, R.L. and Spence, J.M., 1994. The effect of temperature on aphid morphology, using a multivariate approach. Eur. J. Ent. 91: 7-22.

Brightwell, R. and Dransfield, R.D., 2015. Aphis nasturtii Buckthorn - potato aphid http://influentialpoints. com/Gallery/Aphis_nasturtii_buckthorn-potato aphid.htm accessed $\overline{15}$ March $\overline{2} 017$.

Dixon, A.F.G., Horth, S. and Kindlmann, P., 1993. Migration in insects - cost and strategies. J. Anim. Ecol., 62:182-190. https://doi.org/10.2307/5492

Dixon, A.F.G. and Thieme, T., 2007. Aphids on deciduous trees. Naturalist's Handbooks 29. Richmond

Dubnik, H., 1991. Aphids - species identification, biology, control. Th. Mann. Gelsenkirchen-Buer.

Fericean, L., M., Palagesiu, I. and Fericean R., 2006. Contributions to aphids determine on computer analysis of morphological characters. Agroprint Timisoara, 459-462.

Fericean, L. M., Rada O., Ostan M., 2012. The behaviour, life cycle and biometrical measurements of Aphis fabae. Res. J. Agric. Sci. 44: 31-37.

Foster, S., 2006. Insecticide resistance and its implications for potato production in the UK. Research Review, Rothamsted Research. British Potato Council.

Kennedy, J.S., Day, M.F. and Eastop, V.F., 1962. A conspectus of Aphids as vectors of plant viruses. Commonwealth Institute of Entomology, London. pp. 114.

Kawada, K., 1997. Polymorphism and morph determination in Minks Ak. editors -Aphids their biology, natural enemies and control, Amsterdam. Elsevier. pp. 255-266.

Lamb, R.J., 2011. Population variability and persistence of three aphid pests of potatoes over 60 years. Canadian Entomol., 143: 91-101. https://doi. org/10.4039/n10-053

Lozier, J.D., Foottit, R.G., Miller, G.L., Mills, N.J. and Roderick, G.K., 2008. Molecular and morphological evaluation of the aphid genus Hyalopterus Koch (Insecta: Hemiptera: Aphididae), with a description of a new species. Zootaxa, 1688: 1-19.

Ozdemir, I., Nihat A., Seval Toros., Nereşet K. and M. Oktay G., 2008. Investigations of the associated between aphids and ants in wild plants in Ankara Province (Turkey). Mun. Ent. Zool. 3: 606-613.

Mehrparvar, M., Madjdzadeh, S.M., Arab, N.M., Esmaeilbeygi, M. and Ebrahimpour, E., 2012. Morphometric discrimination of black legume aphid, Aphis craccivora Koch (Hemiptera: Aphididae), populations associated with different host plants. North-West. J. Zool. 8: 172-180.

Perju, T.L., 2004. The main pests and their integrated control. Academic Press, Cluj Napoca.

Remaudiere, G. and Remaudiere, M., 1997. Cataloque des Ahididae du monde Homoptera Aphidoidea. INRA, Paris

Shiran, E., Mohammad, S.M. and Mehdi, E., 2013. Mutualistic ants (Hymemnoptera: Formicidae) associated with aphids in central and southwestern parts of Iran. J. Crop Protect., 2: 1-12.

Ruiz, C., Lanfranco, D., Carrillo, R. and Parra, L., 2014. Morphometric variation on the Cypress aphid Cinara cupressi (Buckton) (Hemiptera: Aphididae) associated to urban trees. Neotrop Ent., 43: 245. https://doi.org/10.1007/s13744-014-0204-2

Williams, I.S. and Dixon, A., 2007. Life cycles and polymorphism. In: Aphids as Crop Pests (eds. H.F. Van Emden and R. Harrington). CAB International, Cambridge, Massachusetts. USA. https://doi. org/10.1079/9780851998190.0069 